\title{
Urine Osmolarity and Risk of Dialysis Initiation in a CKD Cohort
}

\author{
Lise Bankir $^{a}$ Max Plischke ${ }^{b}$ Nadine Bouby ${ }^{a}$ Martin Haas ${ }^{b}$ \\ aINSERM Unit 1138, Cordeliers Research Center, Paris, France; bivision of Nephrology and Dialysis, \\ Department of Internal Medicine III, Medical University Vienna, Vienna, Austria
}

\begin{abstract}
Key Words
Vasopressin - Water intake - Urine volume - Creatinine clearance $\cdot$ Multivariate sub-distribution hazards model . Competing risk · Vasopressin antagonists (Vaptans)
\end{abstract}

\begin{abstract}
Background: Several experimental studies in rats and a few association studies in humans suggest that the antidiuretic action of vasopressin may accelerate the progression of chronic kidney disease. We undertook a retrospective analysis in a monocentric cohort of 273 patients with chronic kidney disease stages 1-4, focusing on a strong variable of interest, urinary osmolarity, and a strong endpoint, dialysis initiation. Data was analyzed in a multivariate proportional sub-distribution hazards model for competing risk data with appropriate co-variates. Main Results: Over a median follow-up period of 92 months, dialysis was initiated in 105 patients. After adjustments for baseline creatinine clearance, and other confounding factors, a higher risk for initiation of dialysis was found in patients with higher urinary osmolarity. After 72 months, the estimated adjusted cumulative incidence probability for dialysis initiation was 15,24 , and $34 \%$ in patients with baseline urinary osmolarity of 315,510 , and 775 mosm/l, respectively $(p=0.033)$. Key Messages: In this retrospective, longitudinal study, a higher baseline urinary osmolarity was strongly associated with a higher risk of endstage renal disease (after appropriate adjustments). Further, prospective studies are required to evaluate the possible
\end{abstract}

\begin{tabular}{ll}
\hline KARGER 125.5. & $\begin{array}{l}\text { ( 2015 S. Karger AG, Basel } \\
0250-6807 / 15 / 0667-0014 \$ 39.50 / 0\end{array}$ \\
$\begin{array}{l}\text { E-Mail karger@karger.com } \\
\text { www.karger.com/anm }\end{array}$ & $\begin{array}{l}\text { This is an Open Access article licensed under the terms of the } \\
\text { Creative Commons Attribution-NonCommercial 3.0 Un- } \\
\text { ported license (CC BY-NC) (www.karger.com/OA-license), } \\
\text { applicable to the online version of the article only. Distribu- } \\
\text { tion permitted for non-commercial purposes only. }\end{array}$
\end{tabular}

benefit of interventions aiming at reducing urinary osmolarity as a potential treatment for slowing chronic kidney disease progression.

(C) 2015 S. Karger AG, Basel

\section{Background}

General practitioners and even nephrologists rarely consider the daily urine volume or osmolarilty of their patients. Yet, it may make a difference for the kidney to excrete a daily load of 1,000 mosmoles in 1,2 or 3 liters of urine at 1,000, 500 or $333 \mathrm{mosm} / \mathrm{l}$, respectively (plasma osmolarity in the range of 285-300 mosm/l) [1]. The ability of the human kidney to concentrate solutes in the urine several fold above the plasma value allows a significant 'water economy' in the excretion of soluble wastes, the most abundant of which is urea, the main end-product of protein catabolism [2]. There is a wide inter-individual variability in the spontaneous tendency of humans to concentrate urine as well as in their antidiuretic hormone (vasopressin) secretion and their thirst threshold. These characteristics are partly heritable and quite reproducible in each subject over time $[3,4]$.

In the last few years, interest in these urinary characteristics has been stimulated because new tools, such as selective vasopressin V2 receptor antagonists, the 'vaptans,' and a sensitive immuno-assay for measuring

Corresponding author: Lise Bankir

INSERM UMRS 1138, Equipe 2, Centre de Recherche des Cordeliers 15 rue de l'Ecole de Médecine

FR-75006 Paris (France)

E-Mail lise.bankir@inserm.fr 


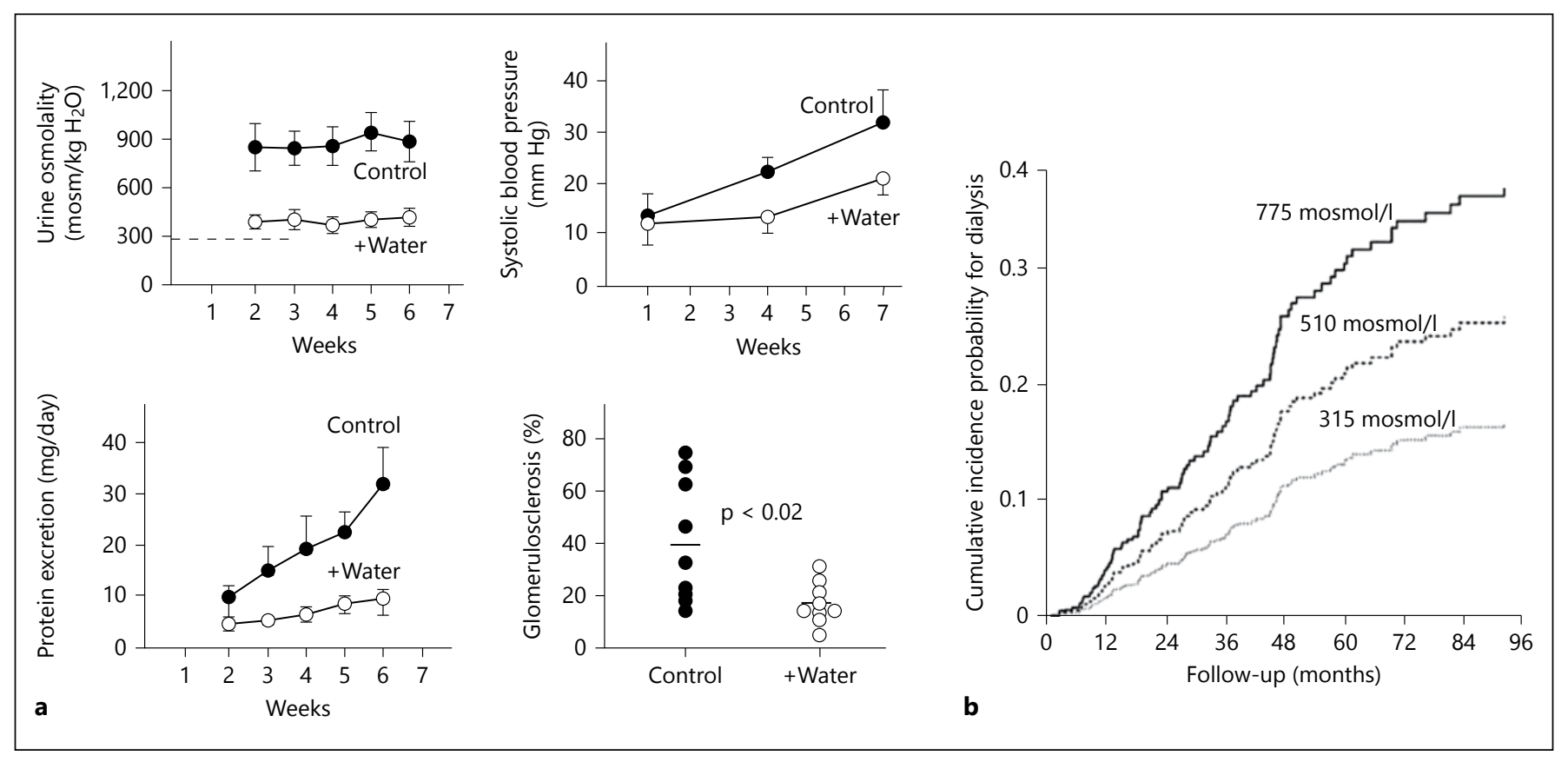

Fig. 1. a In rats with 5/6 nephrectomy (a classical model for initiating progressive $\mathrm{CKD}$ ) a threefold increase in water intake was induced for several weeks by mixing their daily food ration in a water-rich agar gel. Control rats received the same daily amount of dry food and agar without water. All rats had drinking water ad libitum. This protocol significantly reduced vasopressin secretion (not shown) and urine osmolarity, and ameliorated proteinuria, blood pressure and glomerulosclerosis. Adapted after [7]. b In a retrospective study in a cohort of 273 patients with CKD stages $1-4$, the cumulative incidence probability for dialysis initiation during 72 months was significantly greater in those with a high (vs. those with a low) baseline urine osmolarity. The three tracings correspond to values of $\mathrm{eU}_{\mathrm{osm}}$ observed in the10th, 50th and 90th percentiles of $\mathrm{eU}_{\mathrm{osm}}$. Adapted after [12]. copeptin, a surrogate of vasopressin which is co-secreted in equimolar amounts with the hormone, and easier to measure [5] have become available. Moreover, experimental studies in rats have demonstrated an adverse influence of vasopressin in all forms of chronic kidney disease (CKD) [5], and more directly an adverse effect in autosomal dominant polycystic kidney disease [6]. For example, as shown in figure $1 \mathrm{a}$, antagonizing vasopressin's antidiuretic action by increasing fluid intake for several weeks, in addition to reducing urine osmolarity (as intended), also reduced proteinuria, blood pressure and glomerulosclerosis [7]. This prompted several epidemiological studies on the possible associations between different markers of the vasopressin-hydration axis and the decline in renal function, the rise in albuminuria in various cohorts from the general population, in cohorts of kidney transplant patients, or patients with diabetes mellitus. Because urine osmolarity or osmolality (in mosm/l or mosm $/ \mathrm{kg}$ water, respectively) is rarely measured, these studies considered baseline water intake, urine volume, or plasma copeptin concentration [8-11] (see also review in [5]). Altogether, they suggested that a low water intake, a low urine volume, or a high plasma copeptin was associated with a worse kidney outcome [5]. In the new study described below, Haas and colleagues were the first to address this issue in a cohort of patients with overt CKD and were the first to consider baseline urine osmolarity as the variable of interest [12].

\section{Patients and Methods}

The objective of the study was to evaluate, by retrospective analyses, the relationship between urine osmolarity and the risk of initiating dialysis in a cohort of 273 patients with CKD stages 1 to 4. The primary endpoint was time to dialysis (with death as a competing risk). This cohort included all patients attending the Nephrology outpatient Department of the Medical University of Vienna (Austria) for 3 years (January 2000 to December 2002). The median follow-up was 92 months (25th-75th percentiles, 76-95). Patients had a minimum of two visits before and two visits after baseline, each with $24 \mathrm{~h}$ urine collection. Exclusion criteria included urine volume less than $500 \mathrm{ml} / 24 \mathrm{~h}$ and creatinine clearance below $15 \mathrm{ml} / \mathrm{min}$ (= CKD stage 5), leaving 273 eligible patients out of 372 examined. Mortality data and data on the initiation of dialysis until 31/12/2008 were obtained from Austrian 
registries. The baseline value for each variable was the mean of all measurements during a run-in phase of one year (median number of measurements, 5 [3-8]).

As in almost all cohorts of the general population, for patients with $\mathrm{CKD}$, urine osmolarity had not been directly measured at baseline. An estimated urine osmolarity $\left(\mathrm{eU}_{\mathrm{osm}}\right)$ was calculated by an equation based on the sum of the three major urinary solutes making up $90-95 \%$ of the urinary osmoles [13].

$$
\mathrm{eU}_{\mathrm{osm}}=\left(\mathrm{U}_{\mathrm{Na}}+\mathrm{U}_{\mathrm{K}}\right) * 2+\mathrm{U}_{\text {urea }}
$$

where $U_{\mathrm{Na}}, \mathrm{U}_{\mathrm{K}}$ and $\mathrm{U}_{\text {urea }}$ are the concentrations in $\mathrm{mmol} / \mathrm{l}$ of $\mathrm{Na}$, $\mathrm{K}$ and urea in $24 \mathrm{~h}$ urine, respectively. Accordingly, $\mathrm{eU}_{\mathrm{osm}}$ unit is mosm/l (assuming complete dissociation of $\mathrm{Na}$ and $\mathrm{K}$ salts). $\mathrm{U}_{\mathrm{Na}}$ and $U_{K}$ are multiplied by 2 to account for the accompanying anions.

The statistical analysis was a multivariate proportional sub-distribution hazards model for competing risk data, according to Fine and Gray [12]. Death during follow-up was the competing risk. The relationship between $\mathrm{eU}_{\mathrm{osm}}$ at baseline and risk for dialysis initiation during follow-up was adjusted for possible confounding variables (see below).

\section{Results}

Baseline characteristics of the 273 patients are presented in table 1 . In this cohort, $25 \%$ of the variance of all $\mathrm{eU}_{\mathrm{osm}}$ values during baseline was explained by random variation within patients, and $75 \%$ by inter-individual variance. $\mathrm{eU}_{\mathrm{osm}}$ correlated negatively with $24 \mathrm{~h}$ urine volume $(\mathrm{r}=-0.45, \mathrm{p}<0.001)$ and positively with creatinine clearance $(\mathrm{r}=0.60, \mathrm{p}<0.01)$. Median $\mathrm{eU}_{\mathrm{osm}}$ was higher in men than in women (522 vs. 458 mosm/l, respectively, $\mathrm{p}<$ 0.01 ) (as already reported in a number of studies in healthy subjects) [4]; it was lower in subjects with diuretics (490 vs. $520 \mathrm{mosm} / \mathrm{l}, \mathrm{p}<0.05$ ) or beta blockers ( 463 vs. 526 mosm $/ 1, \mathrm{p}<0.01$ ) than in subjects without these drugs.

The median follow-up until death or censoring was 92 months (76 to 95). End-stage kidney disease (= dialysis initiation) developed in 105 out of 273 patients (39\%). The cumulative incidence function of end-stage renal disease according to baseline $\mathrm{eU}_{\text {osm }}$ was studied after adjustment for several confounding variables. The most evident was baseline creatinine clearance because urine osmolarity is known to decline progressively as kidney function deteriorates. Other adjustment variables included age, proteinuria, type of underlying renal disease, beta-blocker and diuretic therapies (see table 2). The adjusted subdistribution hazard ratio for initiation of dialysis was 2.04 (95\% confidence interval 1.06 to 3.92) for each doubling of urine osmolarity $(\mathrm{p}=0.03)$. The 10th, 50th and 90th percentiles of $\mathrm{eU}_{\mathrm{osm}}$ corresponded to 315,510 or 775 mosm/l, respectively. After 72 months, the estimated ad-
Table 1. Main characteristics of the 273 patients at inclusion (adapted from [12])

\begin{tabular}{lc}
\hline Variable & Median (Q1-Q3) or \% \\
\hline CKD level, grades 1 to 3a/3b to 4 & $141 / 132$ \\
Age, years & $56(42-67)$ \\
Male, \% & 56 \\
BMI, kg/m ${ }^{2}$ & $26(23-30)$ \\
MAP, mm Hg & $97(93-102)$ \\
Proteinuria, g/24 h & $2.5(0.5-5.6)$ \\
Diabetes mellitus, \% & 23 \\
Underlying kidney disease, \% & \\
$\quad$ Polycystic kidney disease & 7 \\
$\quad$ Diabetic nephropathy & 7 \\
$\quad$ Glomerular disease & 36 \\
Other, or unknown & 50 \\
Medications, \% & \\
$\quad$ ACEI/AT-II blocker & 85 \\
$\quad$ Diuretics & 47 \\
Beta-blocker & 47 \\
Urine & \\
$\quad$ Urine volume, $1 / 24 \mathrm{~h}$ & $2.2(1.9-2.9)$ \\
eU $U_{\text {osm }, \text { mosm/l } \mathrm{H}_{2} \mathrm{O}}$ & $510(414-622)$ \\
Osmolar excr., mosm/24 h & $1,200(930-1,412)$ \\
Sodium excr., mmol/24 h & $201(141-251)$ \\
\hline
\end{tabular}

Table 2. Independent effect of urine osmolarity, age, protein excretion, kidney function, renal disease, and different drugs on the risk of initiating dialysis in the competing risk regression analysis (adapted from [12])

\begin{tabular}{lll}
\hline Variable & SH ratio [95\% CI] & $\mathrm{p}$ value \\
\hline Urine osmolarity (per doubling) & $2.04[1.06-3.92]$ & $\mathrm{p}=0.03$ \\
Age (per decade) & $0.87[0.74-1.02]$ & $\mathrm{p}=0.08$ \\
Proteinuria (per doubling) & $1.85[1.60-2.13]$ & $\mathrm{p}<0.001$ \\
Creatinine clearance (per doubling) & $0.15[0.09-0.23]$ & $\mathrm{p}<0.001$ \\
Renal disease (CKD vs. other diseases) & $3.44[1.73-6.81]$ & $\mathrm{p}<0.001$ \\
Beta-blocker therapy (yes vs. no) & $1.54[0.97-2.43]$ & $\mathrm{p}=0.07$ \\
Diuretic therapy (yes vs. no) & $1.62[1.03-2.55]$ & $\mathrm{p}=0.04$ \\
\hline
\end{tabular}

justed cumulative incidence probability of dialysis was $15 \%, 24 \%$, and $34 \%$ in patients with a baseline $\mathrm{eU}_{\text {osm }}$ equal to these three percentiles, respectively. Figure $1 \mathrm{~b}$ displays the cumulative incidence probabilities of dialysis initiation for these three levels of baseline $\mathrm{eU}_{\text {osm. }}$.

The major strengths of this study are as follows. The dependent variable, urine osmolarity, is a direct reflect of vasopressin's action on the kidney. The baseline values are very strong because they are issued from several measurements over a 1 year run-in phase (most epidemiologic studies rely on only one measurement at baseline). 
The endpoint (initiation of dialysis) is also stronger than in most studies about CKD progression, and the followup period is quite long. Finally, an elaborate statistical analysis was used, taking into account the competing risk of death. One limitation of this study is the high event rate observed in this cohort. It is possibly explained by the relatively high baseline proteinuria in patients referred to our clinic. Whether the conclusions of this study extend to other cohorts is unknown and should be evaluated.

\section{Interpretation and Conclusion}

Among patients with CKD of various etiologies, for an equal level of remaining renal function, those with higher urine osmolarity at baseline (and thus presumably a stronger influence of vasopressin on the kidney) were more likely to progress to dialysis during subsequent years. Why would vasopressin and/or a high urine concentration contribute to kidney disease progression? Experimental studies in rats, and a few observations in healthy humans undergoing clinical investigations have shown that vasopressin, through its V2 receptors (those responsible for its antidiuretic action on the kidney) induces a rise in GFR. Conversely, an increased hydration that lowers vasopressin secretion significantly lowers
GFR $[14,15]$. The vasopressin-induced 'hyperfiltration' results in the same vicious circle as that induced by a high protein diet [16]. This diet results in an increased load of nitrogen wastes (urea, ammonia, uric acid) and some organic wastes (phosphate) that are not only excreted by the kidney, but concentrated in the urine. Thus, as discussed elsewhere, the deleterious influence of a high protein diet on the diseased kidney may well be due to the enhanced secretion of vasopressin observed in this condition [5]. The kidney's concentrating activity is a potentially modifiable risk factor. Interventional studies in CKD patients, intended to reduce vasopressin's antidiuretic influence and urine osmolarity, are greatly needed in order to evaluate if the benefits observed in animal studies and suggested by retrospective epidemiological studies are effective in slowing the progression of kidney disease.

\section{Funding Source}

This manuscript corresponds to the presentation given during the $\mathrm{H} 4 \mathrm{H}$ meeting on July 2nd, 2014, in Evian, France.

\section{Disclosure Statement}

All authors declare that they have no conflict of interest.

\section{References}

$\checkmark 1$ Bankir L: Antidiuretic action of vasopressin: quantitative aspects and interaction between V1a and V2 receptor-mediated effects. Cardiovasc Res 2001;51:372-390.

$\checkmark 2$ Bankir L, Bouby N, Trinh-Trang-Tan MM, Ahloulay M, Promeneur D: Direct and indirect cost of urea excretion. Kidney Int 1996; 49:1598-1607.

3 Zerbe RL, Miller JZ, Robertson GL: The reproducibility and heritability of individual differencesin osmoregulatory function in normal human subjects. J Lab Clin Med 1991;117:51-59.

4 Perucca J, Bouby N, Valeix P, Bankir L: Sex difference in urine concentration across differing ages, sodium intake, and level of kidney disease. Am J Physiol Regul Integr Comp Physiol 2007;292:R700-R705.

5 Bankir L, Bouby N, Ritz E: Vasopressin: a novel target for the prevention and retardation of kidney disease? Nat Rev Nephrol 2013; 9:223-239.

$\checkmark 6$ Torres VE: Vasopressin antagonists in polycystic kidney disease. Semin Nephrol 2008;28: 306-317.

7 Bouby N, Bachmann S, Bichet D, Bankir L: Effect of water intake on the progression of chronic renal failure in the $5 / 6$ nephrectomized rat. Am J Physiol 1990;258(4 Pt 2): F973-F979.

8 Clark WF, Sontrop JM, Macnab JJ, Suri RS, Moist L, Salvadori M, Garg AX: Urine volume and change in estimated GFR in a communitybased cohort study. Clin J Am Soc Nephrol 2011;6:2634-2641.

-9 Enhörning S, Wang TJ, Nilsson PM, Almgren P, Hedblad B, Berglund G, Struck J, Morgenthaler NG, Bergmann A, Lindholm E, Groop L, Lyssenko V, Orho-Melander M, NewtonCheh C, Melander O: Plasma copeptin and the risk of diabetes mellitus. Circulation 2010; 121:2102-2108.

10 Meijer E, Bakker SJ, de Jong PE, Homan van der Heide JJ, van Son WJ, Struck J, Lems SP, Gansevoort RT: Copeptin, a surrogate marker of vasopressin, is associated with accelerated renal function decline in renal transplant recipients. Transplantation 2009;88:561-567.

11 Velho G, Bouby N, Hadjadj S, Matallah N, Mohammedi K, Fumeron F, Potier L, Bellili-Munoz N, Taveau C, Alhenc-Gelas F, Bankir L, Marre M, Roussel R: Plasma copeptin and renal outcomes in patients with type 2 diabetes and albuminuria. Diabetes Care 2013;36:36393645.

-12 Plischke M, Kohl M, Bankir L, Shayganfar S, Handisurya A, Heinze G, Haas M: Urine osmolarity and risk of dialysis initiation in a chronic kidney disease cohort - a possible titration target? PLoS One 2014;9:e93226.

13 Roussel R, Fezeu L, Marre M, Fumeron F, Jungers P, Lantieri O, Balkau B, Bouby B, Bankir L, Bichet DG: Comparison between copeptin and vasopressin in a population from the community and in people with chronic kidney disease. J Clin Endocrinol Metab 2014; 99:4656-4663.

14 Anastasio P, Cirillo M, Spitali L, Frangiosa A, Pollastro RM, De Santo NG: Level of hydration and renal function in healthy humans. Kidney Int 2001;60:748-756.

15 Bouby N, Ahloulay M, Nsegbe E, Déchaux M, Schmitt F, Bankir L: Vasopressin increases glomerular filtration rate in conscious rats through its antidiuretic action. J Am Soc Nephrol 1996;7:842-851.

16 Brenner BM: Nephron adaptation to renal injury or ablation. Am J Physiol 1985;249(3 Pt 2): F324-F337.
Urine Osmolarity and Risk of Dialysis Initiation in a CKD Cohort
Ann Nutr Metab 2015;66(suppl 3):14-17 DOI: $10.1159 / 000381240$ 